\title{
APLICAÇÃO DA FERRAMENTA DE AVALIAÇÃO DA IMPLEMENTAÇÃO DA CONSTRUÇÃO ENXUTA EM TRÊS EMPRESAS CONSTRUTORAS GOIANAS
}

\author{
Application of the Lean Construction Assessment Tool in \\ three construction companies from Goiânia
}

\author{
Tatiana Gondim do AMARAL ${ }^{1}$, Lucas Barros de PAIVA ${ }^{2}$, Rafael Figueiredo de PAULA ${ }^{3}$, \\ Rodrigo Fernandes NOBRE ${ }^{4}$
}

Recebido em 26 de fevereiro de 2019; aceito em 02 de julho de 2019; disponível on-line em 30 de dezembro de 2019.

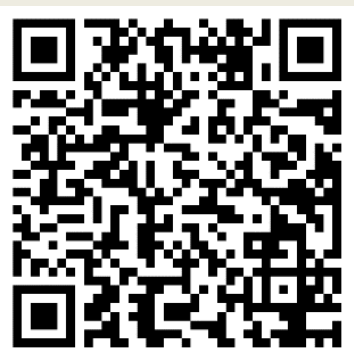

PALAVRAS CHAVE:

Construção enxuta;

Melhoria contínua;

Ferramenta de avaliação;

Análise dos dados;

Resultados.

\section{KEYWORDS:}

Lean Construction;

Continuous improvement;

Assessment tool;

Data analysis;

Results.

\begin{abstract}
RESUMO: As práticas da construção enxuta vêm sendo difundidas de forma progressiva na indústria da construção civil e, com isso, surge a indispensabilidade de mecanismos que permitam a avaliação de sua implementação. As empresas podem aplicar os princípios da Lean Constuction possibilitando os meios para uma melhoria contínua de seus resultados em termos de prazos, custos e demanda ao cliente. O objetivo do trabalho é aplicar a ferramenta de avaliação da implementação da Construção Enxuta (LCAT) em três empresas construtoras goianas. A pesquisa é classificada como quantitativa e qualitativa, aplicada e de caráter exploratório. A partir da análise dos dados referentes à média de todas as quatro categorias (Gestão da Qualidade, Gestão da Cadeia de Suprimentos, Planejamento e Controle da Produção e Gestão de Projetos), as empresas B e C apresentaram percentuais próximos entre si, correspondendo a $61 \%$ e $62 \%$, respectivamente. Esses resultados foram superiores ao da empresa $A$, equivalendo a 53\%. A principal contribuição da pesquisa constituiu em evidenciar as práticas para a implementação da Lean Construction nas empresas pesquisadas e despertar a estas indicações de ferramentas que podem ser facilmente implementadas a um baixo custo.
\end{abstract}

ABSTRACT: The practices of lean construction have been progressively diffused in the civil construction industry, and with this, comes up the indispensability of mechanisms that allow the evaluation of their implementation. Companies can apply the principles of Lean Constuction by enabling them to continuously improve their results in terms of deadlines, costs and customer demand. The objective of this work is to apply the Lean Construction Assessment Tool (LCAT) in three construction companies in Goiás. The research is classified as quantitative and qualitative, applied and exploratory. Based on the analysis of the data for the average of all four categories (Quality Management, Supply Chain Management, Production Planning and Control and Project Management), companies B and C had close percentages, corresponding to $61 \%$ And $62 \%$, respectively. These results were superior to that of company $A$, equivalent to $53 \%$. The main contribution of the research was to highlight the practices for the implementation of Lean Construction in the companies surveyed and to awaken to these indications of tools that can be easily implemented at a low cost.

\footnotetext{
* Contato com os autores:

'e-mail: tatiana_amaral@hotmail.com (T. G. Amaral)

Professora Doutora da Escola de Engenharia Civil e Ambiental da Universidade Federal de Goiás - UFG.

2e-mail: lucasbarros12@hotmail.com (L. B. Paiva)

Estudante de graduação em engenharia civil, Universidade Federal de Goiás.

${ }^{3}$ e-mail: rafaelfig21@outlook.com (R. F. Paula)

Estudante de graduação em engenharia civil, Universidade Federal de Goiás.

${ }^{4}$ e-mail: rodrigosfn@gmail.com (R. F. Nobre)

Estudante de graduação em engenharia civil, Universidade Federal de Goiás.
} 


\section{INTRODUÇÃO}

Os primeiros trabalhos com intuito de adaptar os princípios da produção enxuta à construção civil foram realizados por Koskela (1992). A partir desse trabalho, foram desenvolvidos métodos de avaliação de empresas do ramo. Destaca-se o Protocolo de Avaliação do uso de práticas da construção enxuta, realizado por Etges (2012). Nesse Protocolo, é feito um apanhado de categorias de práticas a serem avaliadas na construção civil, a partir de uma revisão bibliográfica específica (CAMARGO FILHO, 2017).

A utilização das práticas da Construção Enxuta vem sendo difundida de forma gradual na indústria da construção e, com isso, surge a necessidade da criação de mecanismos que permitam a avaliação de sua implementação e também a identificação dos pontos fortes e fracos da implantação do processo de Construção Enxuta (ETGES et al., 2013).

Apesar do crescente desenvolvimento de métodos de avaliação das empresas, em relação ao uso do pensamento enxuto, observa-se que ainda existem poucas publicações que tratam desta questão. Várias ferramentas foram desenvolvidas para avaliar as práticas enxutas e, assim, permitir a detecção de possíveis pontos passíveis de melhoria e aprimoramento.

Visando identificar essas lacunas buscouse reunir diferentes tipos de questionários, com intuito de realizar uma comparação nos métodos de aplicação que se relacionam com a construção enxuta.

Salem et al. (2006) faz uma comparação entre a produção enxuta e a construção enxuta,. Segundo o autor, para medir o grau de aplicação da construção enxuta, deve-se basear em seis elementos principais: Sistema de Planejamento e Controle da Produção, Aumento da Visualização, Huddle Meetings, Estudos Inéditos, Cinco Sensos, Ferramentas à prova de falhas para maior qualidade.

O trabalho apresentado pelos autores teve como principal objetivo implementar e avaliar os valores de diferentes técnicas da construção enxuta apresentadas anteriormente, em uma empresa de Ohio (EUA). Após a aplicação dos princípios, foi feito um gráfico de radar, comparando a situação inicial do projeto, a situação esperada e a situação atual dos seis elementos indicados no trabalho. Portanto, o conjunto de técnicas utilizado na empresa citada pode ser utilizado em outras empresas, com as devidas modificações (SALEM et al., 2006).

A construção enxuta apresenta onze princípios propostos por Koskela (1992). Carvalho (2008) propôs a elaboração de um questionário, permitindo a avaliação desses princípios, baseado na percepção do gestor, do engenheiro, trabalhadores, fornecedores, projetistas e clientes. Apesar disso, não há uma conexão evidente entre os princípios de Koskela e o questionário em questão proposto por Carvalho (2008).

Devido às dificuldades de se identificar a implementação da filosofia enxuta em uma empresa da construção, surgiu a necessidade de criação de ferramentas que permitissem a transposição deste obstáculo. Então Carvalho (2008) propôs um questionário que verificasse o estado atual das empresas em relação à construção enxuta. Este questionário foi aplicado à quatro construtoras (duas de Curitiba, uma em Belém e uma em Porto Alegre, Brasil) (CARVALHO, 2008).

Já o trabalho de Valente et al. (2012) apresenta um estudo de caso de uma empresa em Fortaleza, o qual propôs um conjunto de diretrizes para avaliações internas no canteiro de obras sobre o nível de aplicação, implementação e consolidação da filosofia Lean, que já estava incorporada na empresa.

Para que o objetivo pudesse ser alcançado, foi elaborado um checklist para aplicação na empresa que se baseia em sete categorias da construção enxuta: Gestão do Planejamento e Produção, Kanbans, Jidoka, Fluxos, Produção, Transparência e Organização, Limpeza e Segurança. A aplicação do checklist foi realizada mensalmente, com uma escala de pontuação de 0 a 3, além do não aplicável. Os resultados obtidos 
foram compilados e analisados, para que fossem feitas as devidas alterações na empresa (VALENTE et al., 2012).

Após o checklist elaborado por Valente et al. (2012), Etges et al. (2013) conduziram seu estudo, primeiramente, elaborando uma avaliação do protocolo das práticas da construção enxuta, seguido de sua aplicação em uma empresa de construção. A aplicação deste protocolo foi dividida basicamente em utilização de um piloto para identificar as melhorias a serem feitas no protocolo, a aplicação de uma avaliação mais refinada, e, por fim, uma reunião com o gestor da obra para discussão sobre os pontos fortes e fracos do protocolo utilizado.

A partir de um estudo prévio de Etges et al. (2013), foram definidas quinze categorias das práticas da construção enxuta a serem avaliadas, baseadas nos cinco princípios da produção enxuta de Womack e Jones (1996). Essas categorias foram: Recursos Humanos, Aprimoramento Contínuo, Padronização do Trabalho, Segurança do Trabalho, Layout, Controle de Qualidade, Gestão da Logística e da Cadeia de Suprimentos, Tecnologia da Informação e Comunicação, Produção Puxada, Gerenciamento Visual, Controle e Planejamento da Produção, Sustentabilidade, Gestão do Projeto e Desenvolvimento do Produto, Controle de Custos e Fluxo Contínuo.

Tal protocolo teve sua aplicação com a utilização de um fator peso que permitiu uma melhor avaliação do quão enxuta era a empresa de construção em questão. Contudo, devido à aplicação em apenas uma única empresa (Porto Alegre, Brasil), o resultado não pode ser generalizado.

Dois anos após a publicação do trabalho de Valente et al. (2012), foi desenvolvido um trabalho por Amaral, Silva F. e Silva R. (2014). O trabalho desenvolvido busca tornar mais matemáticos os problemas subjetivos inerentes ao pensamento Lean. Seguindo um modelo lógico, foi feito um questionário baseado em princípios da construção enxuta, definidos por Koskela (2000), com a utilização da ferramenta Fuzzy que permite, por meios matemáticos, avaliar empresas que são ou pretendem se tornar Lean.

A avaliação da empresa foi feita por meio da aplicação desse questionário, por pessoas previamente treinadas, com conhecimento sobre a filosofia enxuta e os princípios de Koskela (AMARAL; SILVA F.; SILVA R., 2014).

Com a utilização de um programa computacional (Matlab ${ }^{\circledR}$ ) foi aplicado o método Fuzzy para analisar os dados derivados de 55 práticas aplicadas às empresas de construção. No trabalho em questão foram avaliadas quatro empresas no estado de Goiás. Após a avaliação, foi traçada uma função ponderação com os dados obtidos para definir o quão enxuta era a empresa (AMARAL; SILVA F.; SILVA R., 2014).

Segundo os autores, o método Fuzzy tem caráter qualitativo, similar ao apresentado por Carvalho (2008), porém, utilizando uma escala para avaliar as empresas com onze níveis ao invés de apenas quatro.

Na busca por atualizar e complementar os trabalhos sobre a construção enxuta, Camargo Filho (2017) pretendeu por meio do questionário, avaliar de forma mais precisa o nível de construção enxuta de empresas construtoras, a partir das práticas da produção enxuta de Womack e Jones (1996). Neste, Camargo Filho (2017) fez o uso de diferentes aplicadores em várias empresas goianas para a validação do questionário. Classificou tais empresas de acordo com 4 níveis (NA, 0, 1 e 2 ) de avaliação de práticas enxutas, determinados. 0 presente trabalho utilizou deste questionário para aplicar nas empresas goianas.

A partir dessa revisão, o Quadro 1.1 ilustra questões pertinentes à aplicação do questionário.

O questionário de Camargo Filho (2017) foi produzido a partir da otimização de diversos outros questionários. Como pode ser observado no Quadro 1.1, em relação à "Avaliação dos Princípios", Salem et al. (2006) preferiu não definir a avaliação, Carvalho (2008) e Amaral, Silva F.e 
Silva R. (2014) avaliaram através de Koskela (1992) e Camargo Filho (2017) optou pela avaliação seguindo os princípios de Womack e Jones (1996), assim como Etges et al. (2013).

Observando a "Escala de Avaliação", Etges et al. (2013) optou pela utilização de três níveis (0, 0,5 e 1), Vieira et al. (2012) utilizou quatro níveis (0 a 3) e Amaral, Silva F. e Silva R. (2014) escolheram onze níveis ( 0 a 10). Camargo Filho (2017) por sua vez, preferiu a utilização de quatro níveis (NA, 0, 1 e 2) para facilitar a aplicação do questionário.

Em relação ao "Número de Práticas", os autores elegeram diferentes quantidades. Camargo Filho (2017), avaliando a importância dos questionários anteriores, adotou um total de oitenta e quatro subcategorias a serem avaliadas pelos aplicadores.

Portanto, o Quadro 1.1 demonstra os trabalhos na área de Lean Construction assimilados por Camargo Filho (2017).

\subsection{OBJETIVOS}

Aplicar a ferramenta de avaliação da implementação da Construção Enxuta (Lean Construction Assessment Tool) em três empresas construtoras goianas.

\section{METODOLOGIA}

Esse item apresenta a metodologia do trabalho.

\subsection{CLASSIFICAÇÃO DA PESQUISA}

A pesquisa realizada para o desenvolvimento deste trabalho foi classificada como quantitativa e qualitativa, em decorrência da natureza dos dados.

A pesquisa é aplicada, visto que o conhecimento obtido a partir da mesma será empregado diretamente no âmbito da construção civil.

No que diz respeito aos objetivos e procedimentos, a pesquisa, que tem caráter exploratório, foi realizada por meio de levantamentos baseados em questionários coerentes com o propósito, a partir da coleta de dados e da própria bibliografia referente ao assunto abordado.

\subsection{DELINEAMENTO DA PESQUISA}

Para realização do delineamento da pesquisa, foi feito um fluxograma, contendo as etapas principais do trabalho. O fluxograma é apresentado a seguir (Figura 2.1).

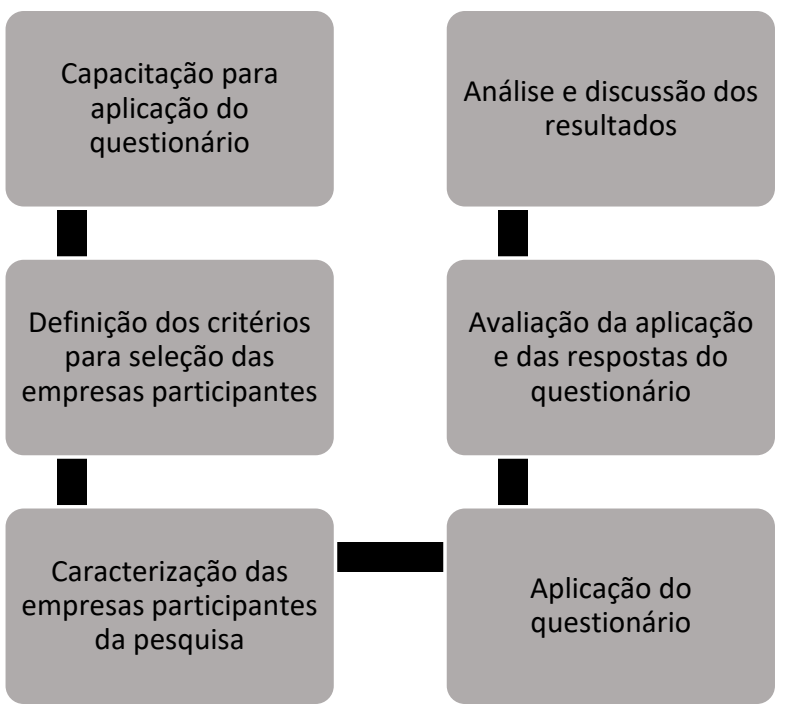

FIGURA 2.1: Delineamento da pesquisa. FONTE: Do autor (2017).

\subsubsection{Capacitação para aplicação do questionário}

O treinamento para aplicação do questionário foi realizado nas aulas da disciplina de Construção Industrializada. Essa disciplina apresenta como ementa o Sistema Toyota de Produção, a aplicabilidade da Filosofia Lean no processo produtivo, a aplicação dos conceitos Lean em edificações e uma discussão da aplicação de ferramentas que permitam a melhoria contínua dos processos. Para que os conceitos fossem assimilados, foram utilizadas 32 horas aula, no curso de Engenharia Civil da Escola de Engenharia Civil e Ambiental (EECA) da Universidade Federal de Goiás (UFG). 


\begin{tabular}{|c|c|c|c|c|c|c|c|}
\hline QUESTIONÁRIOS & Salem et al. (2006) & Carvalho (2008) & Valente et al . (2012) & Vieira et al . (2012) & Etges et al. (2013) & Amaral, Silva F. e Silva R. (2014) & Camargo Filho (2017) \\
\hline Avaliação das Práticas & $\begin{array}{c}\text { Não, questões elaboradas de } \\
\text { acordo com os princípios do } \\
\text { Lean Construction }\end{array}$ & $\begin{array}{l}\text { Não, questões elaboradas de acordo } \\
\text { com os princípios do Lean Construction }\end{array}$ & \begin{tabular}{|c|}
$\begin{array}{c}\text { Sim, questões elaboradas de acordo } \\
\text { com práticas e princíios do Lean } \\
\text { Construction }\end{array}$ \\
\end{tabular} & \begin{tabular}{|c|} 
Sim, questões elaboradas de \\
acordo com práticas e princípios \\
do Lean Construction
\end{tabular} & $\begin{array}{c}\text { Sim, questões elaboradas de } \\
\text { acordo com práticas do Lean } \\
\text { Construction }\end{array}$ & $\begin{array}{l}\text { Não, questões elaboradas de } \\
\text { acordo com os princípios do } \\
\text { Lean Construction }\end{array}$ & $\begin{array}{l}\text { Sim, questões elaboradas de } \\
\text { acordo com práticas do Lean } \\
\text { Construction }\end{array}$ \\
\hline Avaliação dos Princípios & Não há definição & Sim, através de Koskela (1992) & $\begin{array}{l}\text { Sim, através de Koskela (1992) e } \\
\text { Womack e Jones (1990) }\end{array}$ & $\begin{array}{c}\text { Sim, através de Koskela (1992) e } \\
\text { Womack, Jones e Roos (1990) }\end{array}$ & $\begin{array}{l}\text { Sim, através de Womack e Jones } \\
\text { (1996) }\end{array}$ & Sim, através de Koskela (1992) & $\begin{array}{l}\text { Sim, através de Womack e Jones } \\
\text { (1996) }\end{array}$ \\
\hline $\begin{array}{l}\text { Avaliação da Importância } \\
\text { da Prática aos Princípios }\end{array}$ & Não aplicado & Não aplicado & Não, adota pesos iguais & Não, adota pesos iguais & $\begin{array}{l}\text { Sim, foi aplicado um fator peso a } \\
\text { ser avaliado por especialistas }\end{array}$ & Não define & Não, ainda será aplicado \\
\hline Aplicação Piloto & sim & sim & $\begin{array}{l}\text { Não, apenas visitas e entrevistas } \\
\text { com avaliação da performance }\end{array}$ & Não define & sim & Não define & Não, ainda será aplicado \\
\hline Escala de Avaliação & $\begin{array}{c}\text { Seis niveis (não aplicado até } \\
\text { muito alto) }\end{array}$ & $\begin{array}{l}\text { Cinco Níveis ( }(0 \text { a } 4 \text { ) na aplicação do } \\
\text { Piloto e Quatro níveis ( } 0 \text { a } 3 \text { ) nas demais }\end{array}$ & $\begin{array}{c}\text { Cinco niveis ( } 0 \text { a 3, além da categoria } \\
\text { não Aplicável) }\end{array}$ & Quatro niveis ( 0 a 3 ) & Três níveis ( 0 a 1) & Onze níveis (0 a 10) - Lean Score & sim \\
\hline Número de Avaliações & $\begin{array}{l}\text { Não determinado, porém em } \\
\text { um periodo de } 6 \text { meses }\end{array}$ & Aplicação única & $\begin{array}{l}\text { Aplicação mensal, em total de } 5 \\
\text { meses (Junho a Outubro de 2011) }\end{array}$ & 2 Aplicações para cada empresa & Aplicação única & $\begin{array}{l}\text { Não determinado, porém em } \\
\text { um período de } 60 \text { meses }\end{array}$ & Aplicação única \\
\hline $\begin{array}{l}\text { Avalia Práticas Específicas } \\
\text { ou o Sistema em Geral }\end{array}$ & Práticas Específicas & Sistema em Geral & Sistema em Geral & Sistema em Geral & Sistema em Geral & Práticas Específicas & Práticas Específicas \\
\hline Número de Práticas & 24 & Não Informado & 55 & 40 & 105 & 55 & 84 \\
\hline Número de Categorias & 6 & 11 & 7 & 8 & 15 & 11 & 4 \\
\hline Número de Empresas & 1 & 4 & $\begin{array}{l}\text { 1, Entretanto com aplicação em } 4 \\
\text { obras diferentes }\end{array}$ & 2 & 1 & 4 & 17 \\
\hline Local de Aplicação & Ohio, Estados Unidos & $\begin{array}{c}2 \text { em Curitiba, } 1 \text { em Belém e } 1 \text { em Porto } \\
\text { Alegre, Brasil }\end{array}$ & Fortaleza, Brasil & Goiás, Brasil (Anápolis e Goiânia) & Porto Alegre, Brasil & Goiás, Brasil & Goiás, Brasil \\
\hline Tempo de Aplicação & Não definido & 45 minutos a versão atualizada & Não definido & Não definido & $\begin{array}{l}4 \text { Horas para coleta de dados / } 2 \\
\text { Horas para discussão e avaliação }\end{array}$ & Não definido & Não definido \\
\hline $\begin{array}{l}\text { Falhas de } \\
\text { Questionário/Aplicação }\end{array}$ & $\begin{array}{l}\text { Não houve pesos das } \\
\text { diferentes práticas }\end{array}$ & $\begin{array}{l}\text { Não houve utilização do fator peso e } \\
\text { também não houve uma separação de } \\
\text { cada categoria em práticas espećficcas }\end{array}$ & $\begin{array}{l}\text { Não houve pesos das diferentes } \\
\text { práticas }\end{array}$ & $\begin{array}{c}\text { Falta de pesos e de aplicação de } \\
\text { um piloto }\end{array}$ & $\begin{array}{l}\text { Falta de generalização, devido à } \\
\text { aplicação em apenas uma empresa }\end{array}$ & $\begin{array}{c}\text { Deve ser aprimorado, para a } \\
\text { empresa destacar os principais } \\
\text { pontos a serem melhorados }\end{array}$ & $\begin{array}{l}\text { Pesos ainda serão analisados por } \\
\text { especialistas, definição do tempo } \\
\text { de aplicação do questionário }\end{array}$ \\
\hline Tamanho da Empresa & Não Especificado & $\begin{array}{l}3 \text { Empresas de Pequeno Porte e } 1 \text { de } \\
\text { Médio Porte }\end{array}$ & Grande Porte & Médio Porte & Grande Porte & Não Especificado & Todos os portes \\
\hline $\begin{array}{l}\text { Realização de avaliação da } \\
\text { aplicação pelos aplicadores }\end{array}$ & Não & Não & Não & Não & Não & sim & $\operatorname{sim}$ \\
\hline
\end{tabular}

FONTE: Do autor (2017) 


\subsubsection{Definição dos critérios para seleção das} empresas participantes

As construtoras foram definidas conforme alguns pré-requisitos a serem atendidos.

Entre esses requisitos estão: representatividade, importância e participação da empresa na comunidade da construção civil e no mercado regional, localização da empresa no estado de Goiás, que possuíssem o Sistema de Gestão de Qualidade e/ou Sistema de Gestão Ambiental e que possuíssem obras residenciais em execução, que pudessem ser visitadas, possibilitando a aplicação do questionário e levantamento dos dados necessários, e, que possuíssem o interesse na participação.

As 3 empresas selecionadas para aplicação do questionário não só atenderam aos pré-requisitos de participação estabelecidos, mas também foram transparentes na descrição de suas atividades, para que fosse possivel retratar um cenário real quanto a aplicação das práticas Lean abordadas.

\subsubsection{Caracterização das empresas participantes da pesquisa}

Antes de iniciar a discussão dos resultados, foram levantados os dados principais das três empresas participantes como: no de obras em andamento, certificações próprias da gestão, ano de fundação da empresa e outros fatores.

\section{EMPRESA A}

A empresa A possui 30 anos de mercado e tem se preocupado com a gestão interna. A incorporadora, que é de médio porte, possui atualmente 5 obras em andamento, sendo que 2 dessas estão sendo entregues. Em janeiro de 2017, um novo empreendimento será lançado.

Trabalham no escritório aproximadamente 40 funcionários, os funcionários da obra se aproximam de 150, além de mais 150 terceirizados.

A empresa possui certificações de ISO 9001, PBQP-H, ISO 14001 e OSHAS 18001. Além disso, possui os departamentos de execução, financeiro, comercial, de planejamento, de compras, de recursos humanos, de gestão da qualidade e inovações tecnológicas.

No que se refere às técnicas de gestão, a empresa possui algumas delas, entretanto não aplicadas de forma documentada. Algumas das técnicas utilizadas conforme informações da empresa são: linhas de balanço, farol, plantas elaboradas com todos da cadeia, padronização de procedimentos de execução, plataforma BIM, utilização de ferramentas e/ou equipamentos que minimizam atividades de fluxo auxiliar, tal como a grua, projeto de logística de canteiro, paletização dos blocos, indicadores com gestão à vista e benchmarking.

\section{EMPRESA B}

A empresa B possui 22 anos de mercado e tem buscado reformulações na parte de planejamento. A empresa é considerada de médio porte e possui atualmente 1 obra em andamento, com início em dezembro de 2011 e previsão de entrega para dezembro de 2017.

O número funcionários da empresa é de 120 , dos quais 15 compõem a equipe do escritório e 105 realizam a administração e execução em obra. Além disso, há aproximadamente 75 funcionários terceirizados no auxílio das obras, compondo um total de 195 funcionários.

A empresa possui nível A do PBQP-H. Além disso, busca expandir o uso da gestão de forma a garantir melhoria nos procedimentos e tarefas executadas em obra. Entretanto, de acordo com o gerente, ainda existe um problema de aceitação da equipe em relação à implantação Lean.

\section{EMPRESA C}

A empresa $C$ possui 20 anos desde sua fundação e tem como marca presente a preocupação não apenas com a parte de gestão, como também com a sustentabilidade. Atualmente, há 1 obra em andamento com início em fevereiro de 2013 e previsão de entrega para o 
ano de 2017. Além disso, há previsão de que duas novas obras se iniciem em 2018.

As certificações adquiridas por esta empresa são: nível A do PBQP-H e ISO 9001. Apesar de possuir os dois certificados, a empresa não se declara Lean.

Em relação ao número de funcionários, há 32 trabalhando no escritório, 84 próprios da empresa trabalhando em obra e 6 terceirizados. A empresa é considerada de médio porte, tendo construído até então uma área equivalente a $380.000 \mathrm{~m}^{2}$.

\subsubsection{Aplicação do questionário}

Foi aplicado o questionário desenvolvido por Camargo Filho (2017). Com a utilização desse método foi possível observar evidências ou não das práticas que constam no questionário possibilitando medir o nível de implementação da Construção Enxuta em cada empreendimento.

As categorias estabelecidas para avaliação foram Gestão da Qualidade, Gestão da Cadeia de Suprimentos, Planejamento e Controle da Produção e Gestão de Projetos. O questionário apresenta as 4 grandes categorias da filosofia Lean, subdivididas em critérios avaliados, como pode ser observado no Quadro 2.1.

Pode ser observado que dentro de cada grande categoria, são definidos os pré-requisitos a serem atingidos pela empresa. Caso os mesmos não sejam atingidos, não é necessário avaliar os critérios subsequentes aos pré-requisitos. Além disso, quando houver mais de um pré-requisito, todos devem ser aplicados à empresa, de tal forma que quando um pré-requisito não for atingido, os critérios seguintes não devem ser analisados.

\begin{tabular}{|c|c|c|}
\hline \multicolumn{3}{|c|}{ QUADRO 2.1: Categorias da filosofia Lean } \\
\hline CATEGORIA & PRÉ-REQUISITO & CRITÉRIOS AVALIADOS \\
\hline \multirow{7}{*}{$\begin{array}{l}\text { Gestão da } \\
\text { Qualidade }\end{array}$} & \multirow{7}{*}{ SGQ Certificado } & Treinamento dos funcionários \\
\hline & & Solução de problemas \\
\hline & & Benchmarking \\
\hline & & Inovação tecnológica \\
\hline & & Avaliação de desempenho \\
\hline & & Políticas motivacionais \\
\hline & & Organização do ambiente de trabalho \\
\hline \multirow{7}{*}{$\begin{array}{c}\text { Gestão da Cadeia } \\
\text { de Suprimentos }\end{array}$} & \multirow{4}{*}{$\begin{array}{l}\text { Definição de critérios para } \\
\text { seleção de fornecedores }\end{array}$} & Seleção de fornecedores \\
\hline & & Relacionamento com fornecedores \\
\hline & & Processo de compra \\
\hline & & Controle de estoque e armazenamento de materiais \\
\hline & \multirow{3}{*}{$\begin{array}{c}\text { Controle de entrega de } \\
\text { materiais }\end{array}$} & Controle do espaço físico \\
\hline & & Distribuição interna de suprimentos \\
\hline & & Controle de custos \\
\hline \multirow{6}{*}{$\begin{array}{c}\text { Planejamento e } \\
\text { Controle da } \\
\text { Produção }\end{array}$} & \multirow{2}{*}{ PCP formalizado } & Planejamento de longo prazo \\
\hline & & Planejamento de médio prazo \\
\hline & \multirow{2}{*}{$\begin{array}{l}\text { Plano de longo prazo } \\
\text { trasnparente }\end{array}$} & Planejamento de curto prazo \\
\hline & & Mapeamento de fluxo de valor \\
\hline & Fluxo geral de atividades & Controle da produção \\
\hline & definido & Controle de custos \\
\hline \multirow{4}{*}{$\begin{array}{l}\text { Gestão de } \\
\text { Projetos }\end{array}$} & \multirow{2}{*}{$\begin{array}{l}\text { Departamento interno } \\
\text { responsável }\end{array}$} & Planejamento do desenvolvimento de projetos \\
\hline & & Compatibilização de projetos \\
\hline & \multirow{2}{*}{$\begin{array}{l}\text { Processo de verificação de } \\
\text { projetos }\end{array}$} & Identificação do valor requerido pelo cliente \\
\hline & & Identificação de problemas em projetos \\
\hline
\end{tabular}


Cabe ressaltar que além dos critérios apresentados, há subcritérios a serem avaliados por cada aplicador. As notas podem variar de 0 a 2, além do nível não aplicável, como ilustrado na Figura 2.2.

Os dados obtidos sofreram uma análise estatística simples por meio da formatação de um gráfico de radar, considerando as notas das três avaliações dos aplicadores dessa pesquisa.

\subsubsection{Avaliação da aplicação e das respostas do questionário}

Etapa foi realizada com a participação dos aplicadores, por meio da avaliação do questionário, utilizando pesquisa online gratuita e analisada pelo autor do questionário. Seis temas foram contemplados: o treinamento oferecido aos aplicadores, a aplicabilidade como um todo, envolvendo o entendimento dos itens tanto por parte do aplicador como dos entrevistados, a facilidade de coleta das fontes de evidência e a possibilidade de avaliação com a escala proposta; o conhecimento dos conceitos lean por parte dos entrevistados, a capacidade de representação da escala de avaliação, a fluidez e o tempo da aplicação.

\subsubsection{Análise e discussão de resultados}

Foi realizado um comparativo entre as três empresas construtoras com relação à média global entre as quatro categorias: Gestão da Qualidade, Gestão da Cadeia de Suprimentos, Planejamento e Controle da Produção e Gestão de Projetos. Os resultados permitiram a visualização da eficiência e uma análise separada por categoria Lean. Além disso, foi feito um gráfico, resultando em uma média Lean de cada empresa, considerando todas as categorias. Foi ainda elaborada uma tabela, composta por média, mediana e moda de todas as empresas, além de um gráfico de radar, com as pontuações referentes a cada categoria e uma pontuação total. No caso do gráfico, foi considerada a pontuação máxima do questionário, portanto com notas variando de 0 a 2.

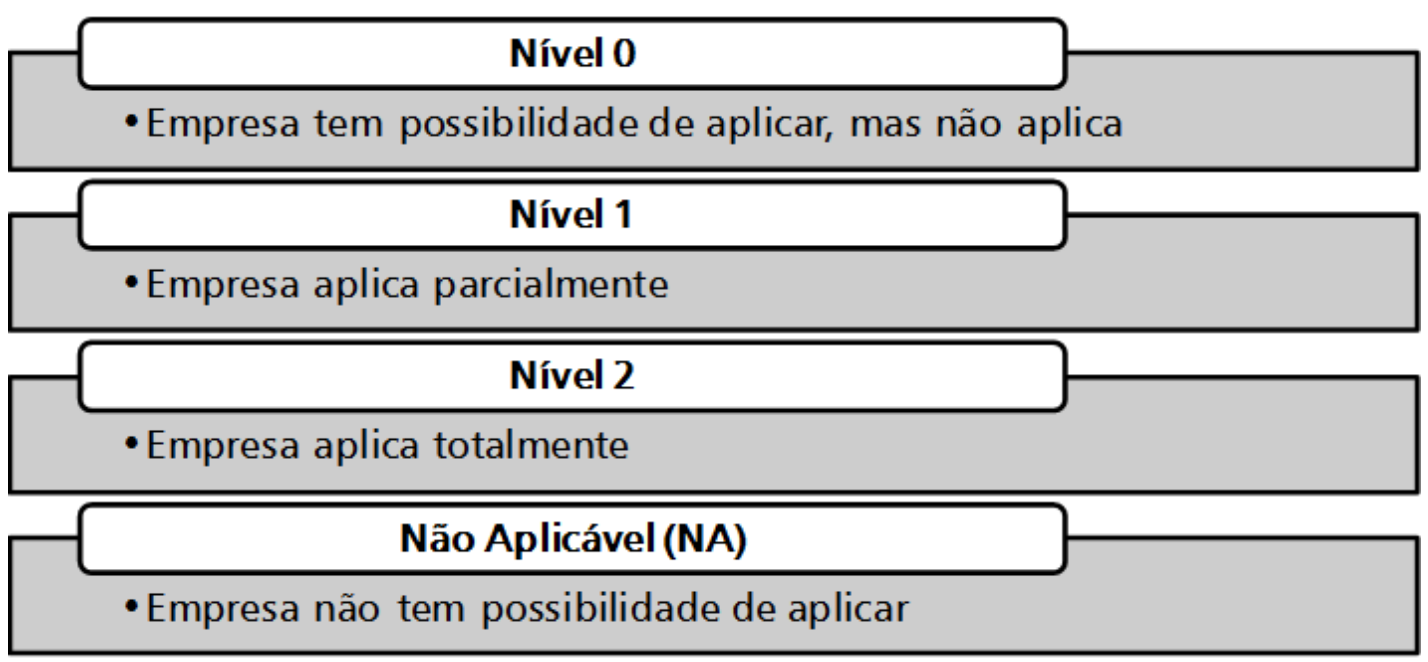

FIGURA 2.2: Níveis de avaliação FONTE: Do autor (2017) 


\section{ANÁlISE DE DADOS E DISCUSSÃO DE RESULTADOS}

\subsection{RESULTADOS DA APLICAÇÃO DO QUESTIONÁRIO}

Após a coleta dos dados gerais, os gerentes de gestão de cada empresa foram entrevistados.

A avaliação foi realizada por três aplicadores, portanto, ao final da aplicação, foram obtidas três notas diferentes. Os aplicadores discutiram as notas a partir dos conhecimentos adquiridos em construção enxuta até que um acordo fosse feito, para obtenção de uma única nota.

Com o questionário avaliado e com a nota consenso para cada um dos subcritérios do questionário, foi feita a média entre os subcritérios, obtendo a nota de cada critério. Entre os critérios de cada uma das 4 grandes categorias, calculou-se novamente a média, obtendo-se dessa forma a média final, ilustrada na Figura 3.1.

Para a compreensão das notas obtidas no gráfico acima, foi disposto um exemplo de cálculo realizado na categoria Gestão de Projetos da empresa B. Primeiramente, foi construída a nota consenso dos subcritérios a partir de uma discussão entre as notas de cada aplicador. Em seguida, foi feita a média aritmética das notas consenso obtidas. Esse resultado é a nota dos critérios da categoria, que nesse caso, são quatro: Planejamento do Desenvolvimento de Projetos, Compatibilização e Validação de Projetos, Identificação do Valor Requerido pelo Cliente e Identificação de Problemas em Projetos. Por fim, calculou-se nova média aritmética entre esses quatro critérios, que correspondeu ao valor de 1,31. Como a nota máxima é igual a 2, a porcentagem final é igual a $\frac{1,31}{2}=66 \%$. A Tabela 3.1 a seguir apresenta as notas e cálculos descritos no texto.

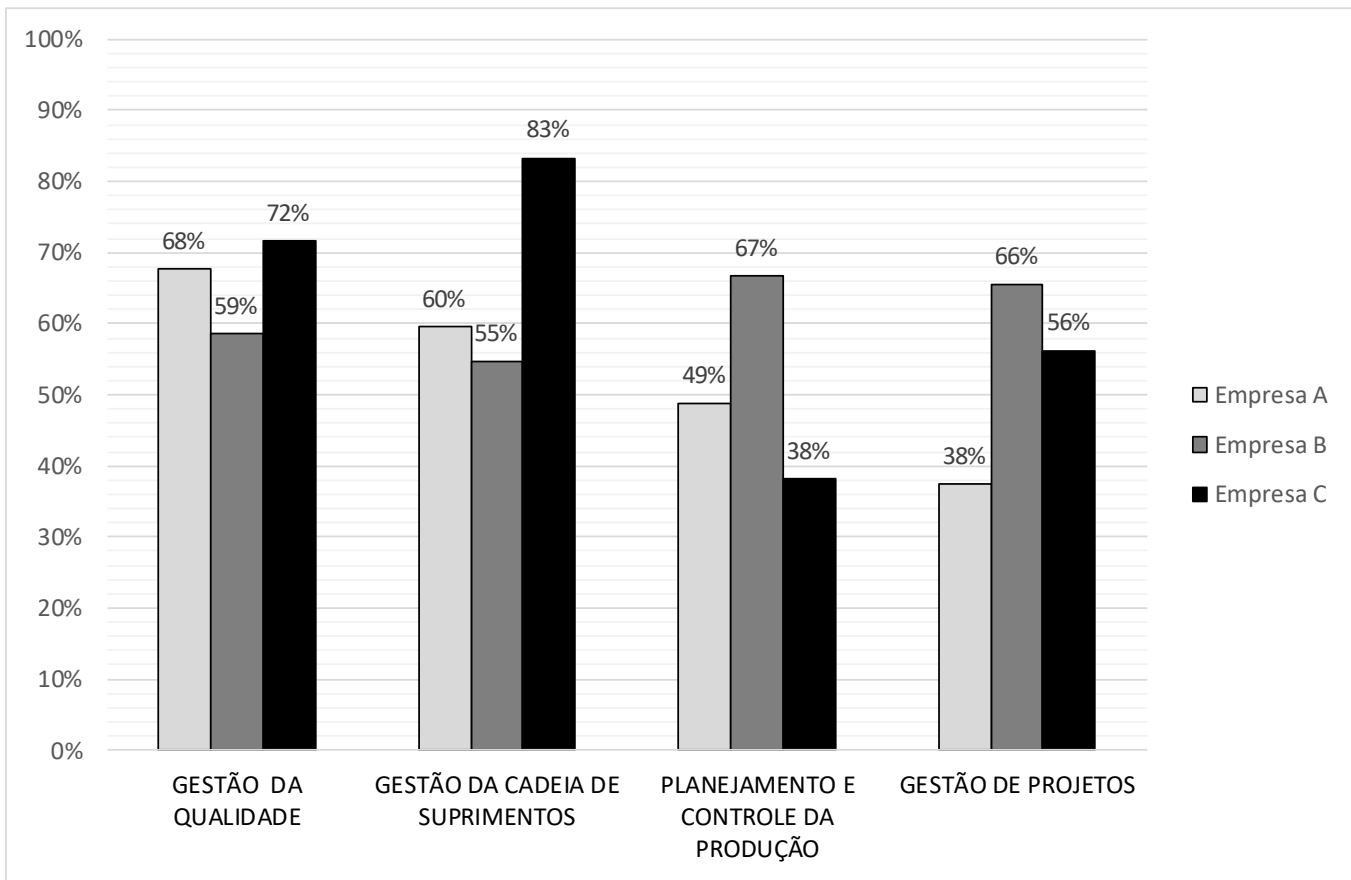

FIGURA 3.1: Média final por categoria para as três empresas FONTE: Do autor (2017) 


\begin{tabular}{|c|c|c|c|}
\hline \multicolumn{4}{|c|}{ TABELA 3.1 - Exemplo de Cálculo } \\
\hline \multicolumn{3}{|r|}{ GESTÃO DE PROJETOS } & \multirow[t]{2}{*}{1,31} \\
\hline Pré-requisito 1 & \multicolumn{2}{|r|}{ Departamento interno responsável pela gestão de projetos } & \\
\hline Pré-requisito 2 & \multicolumn{2}{|r|}{ Processo de verificação de projetos quanto à qualidade e especificações } & \\
\hline \multirow[t]{3}{*}{ Critério 1} & \multicolumn{2}{|r|}{ Planejamento do desenvolvimento de projetos } & 1 \\
\hline & C 1.1 & Planejamento geral do desenvolvimento dos projetos & 2 \\
\hline & C 1.2 & Planejamento semanal das etapas do desenvolvimento de projetos & 0 \\
\hline \multirow[t]{5}{*}{ Critério 2} & \multicolumn{2}{|r|}{ Compatibilização e validação de projetos } & 1,25 \\
\hline & C 2.1 & Verificação de compatibilidade entre projetos antes da aprovação para execução & 1 \\
\hline & C 2.2 & Comunicação direta entre projetistas durante desenvolvimento dos projetos & 2 \\
\hline & C 2.3 & Protótipo físico do produto final onde são testados todos sistemas construtivos & 2 \\
\hline & C 2.4 & Utilização do BIM em projetos para compatibilização entre projetos & 0 \\
\hline \multirow[t]{5}{*}{ Critério 3} & \multicolumn{2}{|r|}{ Identificação do valor requerido pelo cliente } & 1,5 \\
\hline & C 3.1 & Realização de análises de mercado para levantar requisitos esperados pelo público alvo & 2 \\
\hline & C 3.2 & Pesquisas de satisfação de clientes em relação a itens de desempenho do projeto & 2 \\
\hline & C 3.3 & Feedback aos projetistas após pesquisa de satisfação dos clientes & 2 \\
\hline & C 3.4 & Testes de novos itens com utilização de realidade aumentada com clientes potenciais & 0 \\
\hline Critério 4 & \multicolumn{2}{|r|}{ Identificação de problemas em projetos } & 1,5 \\
\hline \multirow[t]{4}{*}{+2} & C 4.1 & Problemas causados por erros de projetos são identificados & 2 \\
\hline & C 4.2 & Comunicação direta entre projetistas e engenheiros de obra durante execução & 2 \\
\hline & C 4.3 & Feedback dos problemas encontrados aos projetistas após execução do empreendimento & 2 \\
\hline & C 4.4 & Metas para redução de problemas causados por erros de projetos & 0 \\
\hline
\end{tabular}

FONTE: Do autor (2017)

Com a análise do gráfico, pode-se listar algumas observações inerentes a cada uma das grandes 4 categorias propostas. Na Gestão da Qualidade, a empresa que mais se destacou foi a Empresa C, com um percentual de $72 \%$. O diferencial da mesma foi o incentivo às atividades externas ao canteiro e uma avaliação completa do desempenho do funcionário. A empresa $A$ apresentou também resultado satisfatório igual a $68 \%$, mostrando desempenho eficaz na parte de solução de problemas, com grupos de solução na obra, padrão a ser seguido nas causas raízes e causas que entram em um ciclo PDCA. A empresa $B$ mostrou desempenho de $59 \%$, o menos eficiente nessa categoria, por não apresentar inovações tecnológicas, com intuito de aumentar a produtividade e também não se preocupar com as causas raízes dos problemas.

Na categoria de Gestão da Cadeia de Suprimentos, as três empresas demonstraram falta de preocupação com o critério do controle de custos na cadeia de suprimentos, de tal forma que nesse critério as notas das empresas $A$ e $C$ foram iguais a 0 , enquanto que a empresa $B$ obteve uma nota próxima a 0 . Apesar da falta de controle de custos, a empresa C novamente apresentou maior destaque nessa grande categoria, tendo a maior pontuação entre todos os resultados, equivalente a uma porcentagem de $83 \%$ dentro da Gestão da Cadeia de Suprimentos. As empresas A e B apresentaram resultados similares. A empresa $A$ não possui datas para realização dos pedidos de materiais em respeito ao lead time do negócio e não há também avaliação periódica do processo de suprimento pela obra. A empresa $B$, por outro lado, não se preocupou com o controle do espaço físico e com a distribuição interna de suprimentos.

Já na área de Planejamento e Controle da Produção, a empresa B mostrou resultado substancialmente superior ao das outras empresas, com percentagem de $67 \%$. A empresa apresentou planejamento mais dividido em longo, médio e curto prazos. $O$ único porém a ser ressaltado dessa empresa, dentro do planejamento de longo prazo, é a não utilização das linhas de balanço, além de um mapeamento de fluxo de valor e controle da produção. A empresa $C$, que ganhou maior destaque nas duas primeiras categorias, não realizou uma divisão adequada do planejamento 
em médio e curto prazos, com notas não eficazes nesses critérios. A empresa A não valorizou o planejamento de médio prazo, fazendo uma ligação direta entre longo e curto prazos. Além disso, não mostrou estratégia para diminuir parcela de atividades sem valor.

Em se tratando da Gestão de Projetos, a empresa $B$ apresentou desempenho mais eficaz com a preocupação com análise de mercado para o levantamento de requisitos esperados pelo público alvo, pesquisas de satisfação de clientes em relação a itens de desempenho de projeto e feedback aos projetistas após a pesquisa de satisfação. Além disso, apresentou desenvolvimento na identificação de problemas nos projetos. A empresa A apresentou resultados críticos nesta categoria, com nota igual a zero na identificação do valor requerido pelo cliente e baixa preocupação com a identificação de problemas em projetos. A empresa $\mathrm{C}$, apesar de estar abaixo da empresa $\mathrm{B}$, mostrou bom resultado da identificação de problemas em projetos. Em relação à compatibilização e validação dos projetos, faltou maior empenho por parte dessa empresa.

Além da análise separada para cada categoria Lean, foi feito um gráfico (Figura 3.2) considerando todas as categorias, com uma porcentagem final de aplicação Lean em cada uma das três empresas. Para isso, foi considerado que cada categoria possui o mesmo peso, portanto alteram igualmente no resultado final.

A partir do gráfico, percebe-se que as três empresas podem aumentar significativamente a aplicação Lean na gestão interna. As empresas B e C, como mostrado também no gráfico anterior, apresentaram porcentagem de aplicação superior à empresa A.

Para melhor visualização das notas obtidas em cada categoria e também uma noção da porcentagem Lean das três empresas foi elaborado um gráfico de radar (Figura 3.3).

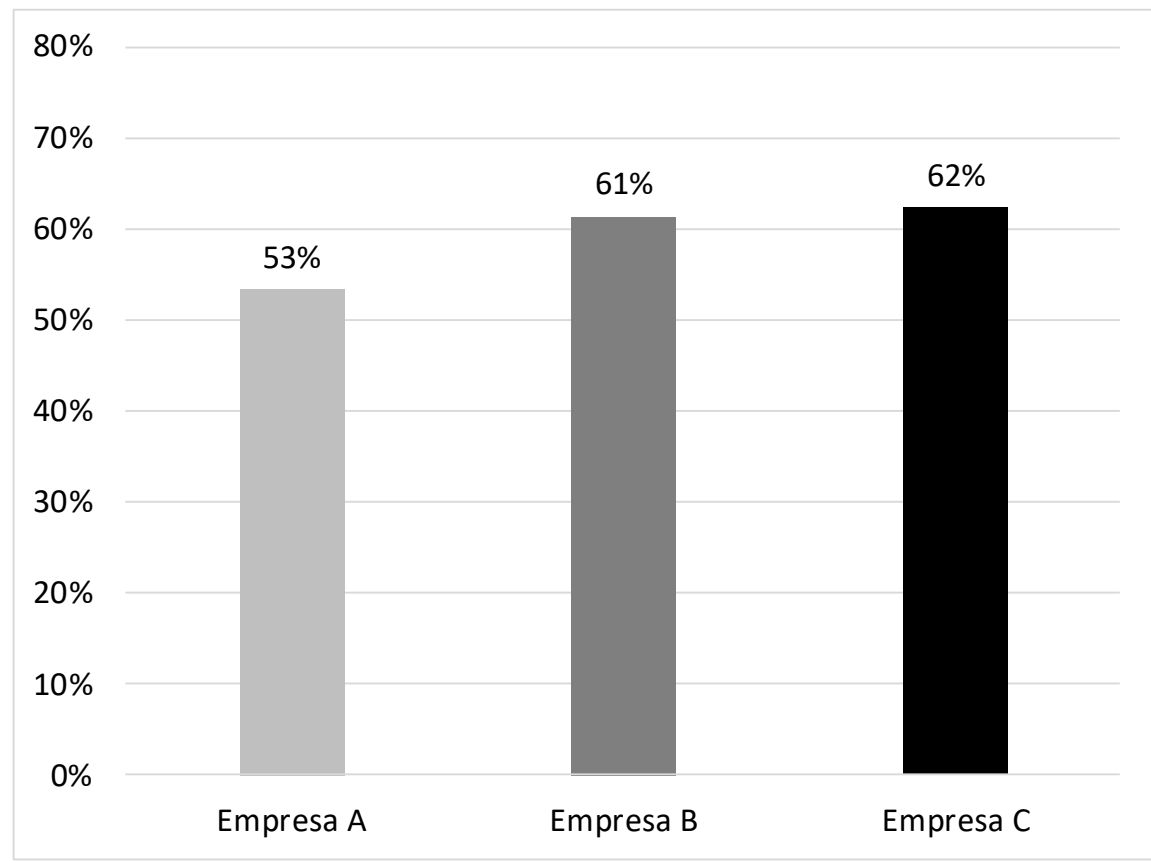

FIGURA 3.2: Porcentagem final de aplicação Lean das três empresas FONTE: Do autor (2017) 


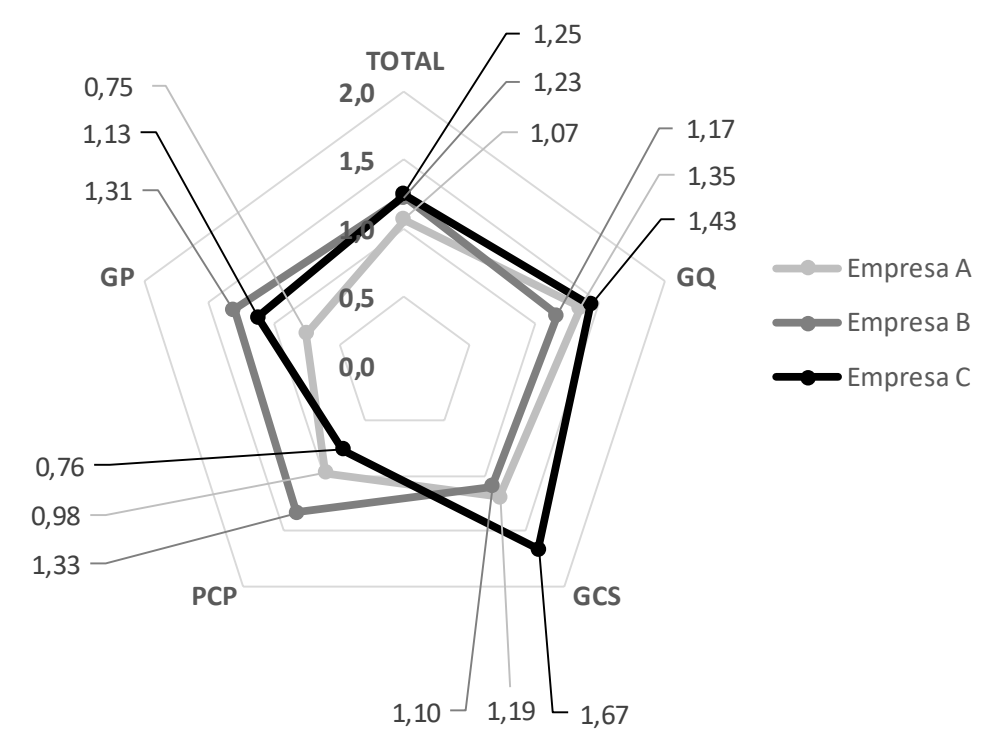

FIGURA 3.3: Notas obtidas em cada categoria - comparativo das empresas FONTE: Do autor (2017)

Os gráficos apresentados até então mostram os resultados finais de cada uma das empresas participantes do questionário proposto por Camargo Filho (2017). Além desses gráficos, foi elaborada uma tabela, com parâmetros conclusivos dentro de cada categoria. Esta tabela é composta por média, mediana, moda, desvio padrão e variância de todas as empresas. A Tabela 3.2 apresenta os demonstrativos capazes de trazer uma discussão final dos dados.

Analisando a Tabela 3.2 e observando os subcritérios avaliados no questionário, podem ser obtidos resultados conclusivos. Ao visualizar a tabela 3.2, percebe-se que a empresa $A$ apresentou nota zero em maior quantidade na parte de Gestão de Projetos. Já a empresa $C$, mesmo com uma média final superior às outras empresas, demonstrou grande quantidade de notas zero no Planejamento da Cadeia de Suprimentos. Isso mostra que essas empresas poderiam aumentar sua porcentagem Lean buscando maior qualidade nas áreas críticas.

\section{TABELA 3.2: Fatores adicionais}

\begin{tabular}{|c|c|c|c|c|c|c|c|c|c|c|}
\hline \multirow{2}{*}{ Empresas } & \multirow{2}{*}{ ITENS } & \multicolumn{3}{|c|}{ MÉDIA } & \multicolumn{3}{c|}{ MEDIANA } & \multicolumn{3}{c|}{ MODA } \\
\cline { 3 - 10 } & & A & B & C & A & B & C & A & B & C \\
\hline GQ & 25 & 1,35 & 1,17 & 1,43 & 2 & 2 & 2 & 2 & 2 & 2 \\
\hline GCS & 22 & 1,19 & 1,10 & 1,67 & 2 & 1 & 2 & 2 & 2 & 2 \\
\hline PCP & 23 & 0,98 & 1,33 & 0,76 & 1 & 2 & 0 & 2 & 2 & 0 \\
\hline GP & 14 & 0,75 & 1,31 & 1,13 & 0 & 2 & 2 & 0 & 2 & 2 \\
\hline TOTAL & $\mathbf{8 4}$ & $\mathbf{1 , 0 7}$ & $\mathbf{1 , 2 3}$ & $\mathbf{1 , 2 5}$ & $\mathbf{1}$ & $\mathbf{2}$ & $\mathbf{2}$ & $\mathbf{2}$ & $\mathbf{2}$ & $\mathbf{2}$ \\
\hline
\end{tabular}

Categorias: GC = Gestão da Qualidade; GS = Gestão da Cadeia de Suprimentos; PCP = Planejamento e Controle da Produção; GP = Gestão de Projetos 


\section{CONCLUSÕES}

O presente trabalho pôde auxiliar na validação do questionário de Camargo Filho (2017), com a aplicação do mesmo em três empresas construtoras goianas. Estas apresentaram porcentagens do Lean Construction, considerando todas as categorias, superiores a $50 \%$.

A partir da análise e discussão dos resultados foi observado que a Empresa $A$ teve seu maior resultado relacionado à Gestão da Qualidade, com uma porcentagem de 68\% e menor resultado em Gestão de Projetos, com 38\%. A empresa $B$, por sua vez, teve sua melhor nota relacionada a Planejamento e Controle de Produção com $67 \%$ e a menor nota em Gestão da Cadeia de Suprimentos, com 55\%. E a Empresa C apresentou seu menor desempenho igual a 38\%, em Planejamento e Controle da Produção. O seu maior aproveitamento foi em Gestão da Cadeia de Suprimentos, obtendo o equivalente a $83 \%$, resultado de eficiência considerável.

Durante o desenvolvimento da pesquisa foram encontradas algumas limitações que interferiram no resultado da mesma. As reuniões com as empresas A e C, por exemplo, foram realizadas no escritório da construtora e, portanto, não foi possível a constatação dos itens do questionário aplicados na prática. Assim, estas empresas foram avaliadas com o entendimento e honestidade dos entrevistados, tendo alguns de seus valores podendo não ser a representação fiel da realidade. Outro problema encontrado, relacionado à empresa $C$, foi a dificuldade dos aplicadores em avaliar os itens com a nota "1" (referente a possuir parcialmente a aplicação do item). Isso porque as respostas fornecidas eram, em sua maioria, "sim" ou "não". Mais uma vez, um problema intimamente ligado a não possibilidade de visualização das obras.

A validação do questionário foi feita através de uma plataforma online e gratuita, compilada pelo próprio Camargo Filho (2017).

Este trabalho tem como principal contribuição para o campo da engenharia civil, evidenciar as práticas para a implementação da Lean Construction nas empresas pesquisadas e despertar a estas indicações de ferramentas que podem ser facilmente implementadas a um baixo custo.

\section{REFERÊNCIAS BIBLIOGRÁFICAS}

AMARAL, T. G.; SILVA, F. M. A.; SILVA, R. S. M. Fuzzy logic applied to Lean construction - An implementation in building companies. Journal of Civil Engineering and Architecture Research. v. 1, n. 1, p. 37-44, 2014

CÂMARA BRASILEIRA DA INDÚSTRIA DA CONSTRUÇÃO. Construção enxuta pode reduzir custos. Net, Ceará, set. 2014. Disponível em: < http://www.cbic.org.br >. Acesso em: 01 set. 2016

CAMARGO FILHO, C.A.B. LCAT: Ferramenta de Avaliação da Implementação da Construção Enxuta. 2017. 99 f. Dissertação (Mestrado em Engenharia Civil) - Programa de Pós Graduação em Geotecnia, Estruturas e Construção Civil, Universidade Federal de Goiás, Goiás, 2017.

CARVALHO, B. S. Proposta de uma ferramenta de análise e avaliação das construtoras em relação ao uso da construção enxuta. 2008. 141 f. Dissertação (Mestrado em Engenharia Civil) - Curso de Pósgraduação em Construção Civil, Universidade Federal do Paraná, 2008.

ETGES, B. M. B. S. Protocolo de auditoria do uso de práticas da construção enxuta. 2012. 85 f. Tese (Mestrado em Engenharia da Produção) - Escola de Engenharia Civil, Universidade Federal do Rio Grande do Sul, Porto Alegre, 2012.

ETGES, B. M. B. S.; SAURIN, T. A.; BULHÕES, I. R. A protocol for assessing the use of Lean construction practices. In: 21th Annual Conference of the IGLC, Fortaleza, Brazil. Proceedings... Fortaleza, Brazil. 2013.

IBGE. Instituto Brasileiro de Geografia e Estatística. Disponivel em: < http://www.ibge.gov.br >. Acesso em: 01 jun. 2017

IGLC. The International Group for Lean Construction. Disponível em: < http://www.iglc.net >. Acesso em: 01 fev. 2017.

KOSKELA, L. Application of the new production philosophy to construction. Stanford Center for Facility Engineering, TECHNICAL REPORT 72, 1992.

KOSKELA L. An exploration towards a production theory and its application to construction. Dissertation for the degree of Doctor of Technology at Helsinki University of Technology - Espoo: Technical Research Centre of Finland. Finland, 2000. 
SALEM, O.; SOLOMON, J.; GENAIDY, A.; MINKARAH, I. Lean Construction: From Theory to Implementation. Journal of Management in Engineering, v. 22, n. 4, p. 168-175, 2006.

SOLOMON, J. A. Application of the principle of Lean Production to construction. Construction Engineering and Management Program, Department of Civil and Environmental Engineering, College of Engineering, B.S.C.E, University of Cincinnati, Cincinnati, 2004.

VALENTE, C.; NOVAES, M.; MOURÃO, C. A.; NETO, J. Lean monitoring and evaluation construction site: a proposal of Lean audits. In: 20th Annual Conference of the IGLC, San Diego, USA. Proceedings... San Diego, USA. 2012.

VIEIRA, L. C.; DE SOUZA, L. O.; AMARAL, M. T. Application of the Rapid Lean Construction-Quality Rating Model to Engineering Companies. In: 20th Annual Conference of The International Group for Lean Construction. San Diego, USA. 2012.

WOMACK, J. P.; JONES, D. T. Beyond Toyota: How to root out waste and purse perfection. Harvard Business Review. v. 74, n. 5, p. 140-158, Sept./Oct. 1996. 